\title{
ARE WE HAPPY YET? : RE-EVALUATING THE EVALUATION OF INDIGENOUS COMMUNITY DEVELOPMENT
}

\section{Kerin Gould University of California, Davis}

As I was working on research into Indigenous community development, I wanted to get an overview of how things are going - are projects improving well-being? What is working and what isn't? I found I couldn't get a clear multi-dimensional picture. So I had to wonder, about evaluation criteria and what the alternatives were. How can we, as academics and researchers and allies, make sense of the available information in such a way that our work is meaningful to the Indigenous communities we work with?

As academics, our work can affect processes and practices carried out in the different ethnic communities that we work with. We can make ourselves more useful and relevant if we recognize that these peoples have their own measurements and criteria and work their concepts into our methods and analyses. It is tempting to claim egalitarian ideals as the reason for using the same measurements for deeply different peoples, as if we all prioritize goals identically and organize using the same protocols, but it can also negate significant aspects of cultural and individual identities and can result in misleading interpretations. Conventional melting- 
pot thinking on diversity often implies that everyone basically wants the same things, assuming Euro-American values represent universal goals. This assumption can diminish community satisfaction with a project as has been seen in many cases of top-down development. In spite of globalization, societies are not really melting pots - more like minestrone soup where each ingredient can be savored, even if some would prefer a cream-of-mainstream. Indigenous peoples, for example, live within nation-states and societies that are based on entirely different worldviews, so shouldn't assessment of their unique issues reflect their distinct values and criteria?

In looking at different community development projects of Indigenous peoples throughout the Americas, certain standard indicators paint a rosy picture, but do these add up to improved wellbeing ${ }^{16^{*}}$ according to what the communities in question consider most important for living? What kind of evaluation is useful to ensure that community projects deliver the most meaningful contentment and well-being to Indigenous communities? Most importantly, how can Indigenous people measure whether they are succeeding on their own terms, in ways that respect and support traditional knowledge, philosophy, and social protocols, self-determination, cultural continuance and thriving individuals?

\section{Positive Economic Indicators Show Improvements}

After centuries of the most severe poverty brought about by confiscation of sustaining resources, subjugation to ethnocentric and often unethical laws, categorization as incompetent to manage their own assets, dispersal to cities and proletarianization, assimilation without equality, and the resulting physical/mental/spiritual health damage, some Indigenous people are seeing some improvement and economic success. Certainly Indigenous populations are

$16^{*}$ I use the term "well-being" here to imply a more holistic, inclusive sense and because the term "quality of life" has previously been associated with externally generated criteria which are often, ironically, too quantitative in the hopes of presenting objective and comparable data. "Well-being" can comprise physical, mental, and spiritual health of both the individual and the commiunity collective as well as the contentment with the perceived levels of physical, mental, and spiritual health. Certainly this definition begs a combination of both objective, material criteria as well as subjective and culturally specific criteria. 


\section{Ethnic Studies Review Volume 31}

recovering, some are beginning thrive, and one might say they are developing in ways that parallel those of non-Native counterparts. Many diagnostic methods indicate that Indigenous communities are in better conditions than they were only a few short decades ago, in what might seem like a miraculous economic recovery.

In the US, 2002 Census $^{1}$ reports that 201,387 American Indian/Alaska Native-owned businesses (not including tribally owned businesses, as in the previous census) rang up receipts of $\$ 26,872,947,000$, and as of 2004, there are an estimated 90,730 majority-owned, privately-held firms owned by Al/AN women in the U.S., employing nearly 129,000 people and generating $\$ 12.4$ billion in sales. Between 1997 and 2004, the number of Native American and Alaska Native women-owned firms increased by $69 \%$, employment grew by $73 \%$, and sales rose by $83 \%{ }^{2}$ In 2005 a Harvard University Project On American Indian Economic Development report on socio-economic changes showed that significant material improvements have taken place over the last decade for U.S. Native people as seen in this table:

Changes On Reservations Other Than Navajo

(Changes 1990- 2000 presented in points unless indicated as \%; OTSAs excluded) ${ }^{3}$

\begin{tabular}{|l|l|l|l|}
\hline & Non- Gaming & Gaming & U.S. \\
\hline Real per capita income & $+21 \%$ & $+36 \%$ & $+11 \%$ \\
\hline Median household income & $+14 \%$ & $+35 \%$ & $+4 \%$ \\
\hline Family poverty & -6.9 & -11.8 & -0.8 \\
\hline Child poverty & -8.1 & -11.6 & -1.7 \\
\hline Deep poverty & -1.4 & -3.4 & -0.4 \\
\hline Public assistance & +0.7 & -1.6 & +0.3 \\
\hline Unemployment & -1.8 & -4.8 & -0.5 \\
\hline Labor force participation & -1.6 & +1.6 & -1.3 \\
\hline Overcrowded homes & -1.3 & -0.1 & +1.1 \\
\hline Homes lacking complete plumbing & -4.6 & -3.3 & -0.1 \\
\hline Homes lacking complete kitchen & +1.3 & -0.6 & +0.2 \\
\hline College graduates & +1.7 & +2.6 & +4.2 \\
\hline High school or equivalency only & -0.3 & +1.8 & -1.4 \\
\hline Less than 9th grade education & -5.5 & -6.3 & -2.8 \\
\hline
\end{tabular}


Gould-Are We Happy Yet

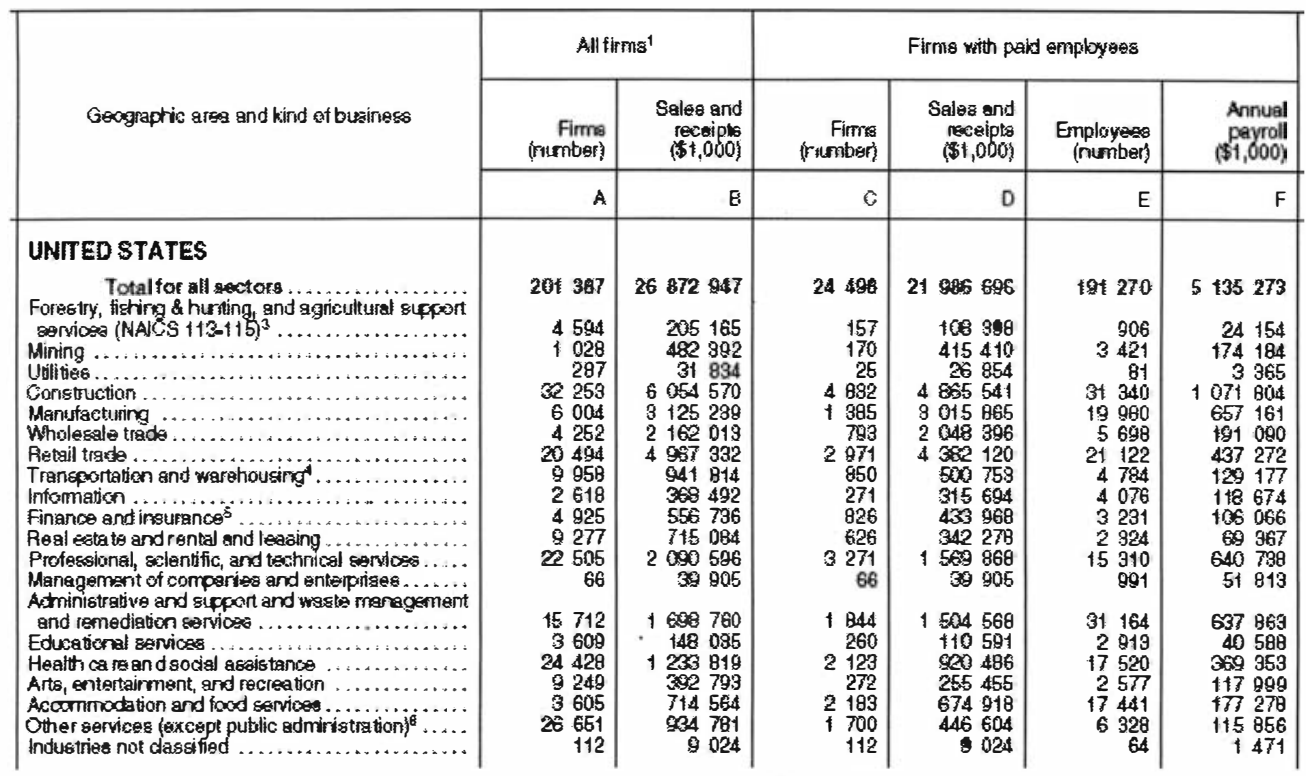

U.S. Census Bureau, American Indian- And Alaska Native-Owned Firms: 2002 Economic Census, Survey Of Business Owners ${ }^{4}$

Gaming is clearly not the only contributor to economic upturn, and in fact non-gaming tribes' average wages are higher as are housing improvements on those reservations. ${ }^{5}$ Throughout the Americas, Native communities and individuals have built up all kinds and sizes of enterprises from wild rice or specialized corn production to small airlines, clothing design, Indigenous music recording companies, radio stations, handmade soaps, software design, legal and technical advising, coca-leaf teas and candies, hotels and eco/cultural tourism, wind farms, adobe construction, sustainable forestry and fisheries, herbal medicines, real estate and banks. ${ }^{6}$

In Canada, the National Aboriginal Environmental Development Board reports that aboriginal enterprise is growing - even faster than the national averages in many fields. There are now over 27,000 Aboriginal entrepreneurs, a 30\% increase from 1996 to 2001, more than nine times that of the Canadian average. ${ }^{7}$ The number of manufacturing, transportation and warehousing businesses was almost five times higher in 2001 than in 1996, and the number of Aboriginal businesses operating in professional, scientific and 


\section{Ethnic Studies Review Volume 31}

technical, education, health and social services has more than doubled since 1996.

Many tribally owned businesses are also thriving, often combining several complementary interests such as forestry and a mill or construction business, for example. The Wisconsin HoChunk tribe invested casino money in diverse businesses - hotels, real estate, stores, two Internet companies, a housing fabrication company, and a telecom hardware company to name a few and generated profit growing from zero to $\$ 25$ million in revenues in five years. ${ }^{8}$

For Central and South America, it is very difficult to find comparable information that distinguishes the entrepreneurship and economic projects of Indigenous individuals and communities as distinct from those of "peasants" or "rural poor". There is, however, lots of discussion on emigration as a major source of income and outside agencies' macro-economic plans and policies to create development for and in the territories of Indigenous people. Still, as in the north, Indigenous people have been increasing their business acumen and expanding markets for goods and services. Emigrants often bring home computers or fax machines with which they can stay in touch with remote clients or maintain networks between the home community and customers abroad. One example is that of the diaspora of people from Otavalo in Ecuador, whose fame as purveyors of Andean textiles has spread with their migrants to Europe and North America. At a California powwow recently, Indigenous vendors from the south were selling warm alpaca sweaters with dream-catcher and eagle designs to appeal to the northern Natives' tastes. While one Comanche vendor said she did not approve of the appropriation of northern Native designs, even by other Indigenous people, others were busy buying.

Behind the business successes, there has been an increase in both technical business assistance/training and loans for community development and individual entrepreneurship. Agencies like the Community Development Financial Institution Fund, part of the U.S. treasury, statewide chambers of commerce, and the Small Business Administration (and in Canada, agencies such as Industry Canada's Aboriginal Business Canada program and the First 


\section{Gould-Are We Happy Yet}

Citizens' Fund in British Columbia) provide a number of support services to Native entrepreneurs and tribal businesses, technical assistance and loans, ${ }^{9}$ networking and conferences.

In addition to business growth, Indigenous people have improved their ability to carry out community projects by working with foundation support. One of the most positive trends for Indigenous economic improvement is an increase in grantmaking, lending and technical assistance. There are programs that provide capacity-building for non-profits and tribal organizers, rotating loan or micro-lending cooperatives, and education for managing family finances. Many of these feature Indigenous people supporting other Indigenous people as allies who can relate to the recipients' organizing styles, goals, needs, philosophies, and problems especially well. In Canada human resource programs have helped thousands return to school or work, and

"Aboriginal Financial Institutions (e.g. Aboriginal Capital

Corporations and Aboriginal Community Futures Development Corporations) currently disburse an impressive $\$ 70$ million in loans to almost 2,000 Aboriginal businesses each year... Aboriginal people and communities continue to negotiate more and more revenue-sharing and impact benefit agreements." 10 In addition to support for businesses, Indigenous communities with a bit of surplus are supporting projects inter-tribally and even across the Americas. Giving, newly constituted as philanthropy, has deep and meaningful roots throughout Native cultures. In communities where a person who has given away a great deal is respected more than one who has accumulated a great deal or where the word "stingy" is the worst possible insult, it is not surprising that in times of economic improvements Native people cultivate and formalize their own giving practices and organize philanthropic support. Tribes and organizations have been able to respond generously to the needs of Native and non-Native people. For example, in October of 2001 Indian Country Today reported on the response from Native tribes to the 9/11 attacks on the World Trade Towers: for example, the Mohegan Tribe of Connecticut donated $\$ 1$ million, the Rumsey Rancheria of California contributed $\$ 200,000$ and the Prairie Band Potawatomi \$100,000, while other 


\section{Ethnic Studies Review Volume 31}

tribes quietly contributed goods and services. ${ }^{11}$ Several tribes, the National Congress of American Indians, and the National Indian Gaming Organization later donated large amounts to support other tribes and non-Native neighbors hit by Hurricane Katrina, although some of those dollars apparently never reached their intended beneficiaries, perhaps lost in the bureaucracy of large-scale disaster relief. ${ }^{12}$ Several other organizations that are mainly Native-run, like the Seventh Generation Fund, Honor the Earth, and First Nations Development Fund support a variety of community projects, while many casino tribes contribute to regional concerns in order to foster goodwill among their neighbors.

On the more technical side of Indigenous networking, a study conducted at lowa State University in 2002 reports that e-commerce helps Indigenous businesses eliminate middlemen and supports networking between other Natives at home, on other reservations and elsewhere. ${ }^{13}$ As this research shows, not only have Indigenous people begun using e-commerce for direct sales of their artisan work or specialty crops and promotion of their eco-tourism offerings, but they are also using their social, cultural, natural and human capital to create and sustain businesses.

\section{Social Indicators Paint a Different Picture}

With all of the economic improvements noted above, one would expect to see equally dramatic improvements reflected in social indicators. Social improvements certainly exist in terms of material improvements and some services. Infant deaths decreased from 15.2 to 8.6 between 1983-2002, and $71 \%$ of expecting mothers received prenatal care. School readiness in 3-5 year olds has gone from $35 \%$ in 1993 to $39 \%$ in 2001, with 5 year olds reaching $71 \%$ and $80.7 \%$ of children use computers at school and $65.2 \%$ use them at home. ${ }^{14}$ These important and long over-due improvements would paint a very rosy picture, and one might be tempted to see examples of economic improvement as a sign that Indigenous peoples' problems have been resolved.

However, in a scan of social indicators, the things that did not improve or worsened were most notable. ${ }^{15}$ Violence against women continues to be a concern of indigenous people that is far from being 


\section{Gould-Are We Happy Yet}

resolved or ameliorated by economic gains. ${ }^{16}$ Striking disparities in quality of life between Native populations and the nations around them hurt not only due to the inadequacies themselves but also in the comparisons as other issues may underlie economic, and social disparities (and vice versa). For example, in Canada where aboriginal unemployment rates continue to be double the national average and incomes are lower than the national levels by 40$50 \%{ }^{17}$, a number of social problems continue to flourish, including the high rates of violence against and disappearance of Indigenous women. Amnesty international attributes this mainly to the social and economic marginalization of Indigenous women that has "pushed a disproportionate number of Indigenous women into dangerous situations that include extreme poverty, homelessness and prostitution," 18 all of which makes them more vulnerable to attack, and unlikely to receive police protection or assistance when attacked. Amnesty International has traced this violence to

"a broader spectrum of social stress and turmoil that has resulted from government policies imposed on Indigenous peoples without their consent....the erosion of culture, the uprooting of generations of Indigenous women, the separation of children from their parents, and a cycle of impoverishment, despair and broken self-esteem that continues to grip many Indigenous families."19

This composite of social problems will not be resolved simply through increased incomes and employment rates.

For Indigenous people in Latin America, though it is again difficult to find disaggregated social indicators, some scattered information can paint a panorama from which to draw ideas if not conclusions. According to Mexico's National Commission for the Development of Indigenous People ${ }^{20}$, over half of Indigenous people survive on minimum wage or less, including a large number with no visible income at all. Without even considering the effects of conspicuous national disparities, it is clear that the modernization of Mexico, benefits (?) of NAFTA and globalization, and even the improvements generated by some Indigenous communities and their allies have not reached all of Indigenous Mexico. These disparities, and resulting urbanization and emigration, exacerbate 


\section{Ethnic Studies Review Volume 31}

relative purchasing power and access to resources for resolving social and health problems, create new family and community breakdowns, dilute identity and collective knowledge bases, diminishing well-being on many levels. A report by World Bank analysts ${ }^{21}$ notes that many poverty-related social indicators are not improving as hoped for:

- Indigenous people recover more slowly from economic crisis.

- The indigenous poverty gap is deeper, and shrank more slowly over the 1990s.

- Being indigenous increases an individual's probability of being poor and this relationship was about the same at the beginning and at the close of the decade.

- Indigenous people continue to have fewer years of education, but the gap is narrowing, and education outcomes are substantially worse for indigenous peoples, which is indicative of problems in education quality. Increases in education do not result in the same gain in earnings for Indigenous people.

- Child labor is still needed by many families and interferes with schooling

- Children continue to suffer from malnutrition.

- Indigenous people, especially women and children, continue to have less access to basic health services.

And the Pan American Health Organization continues to report dismal health conditions and disparities for Indigenous populations. In their report "Health of the Indigenous Population in the Americas", presented to the $138^{\text {th }}$ Session of the Executive Committee in Washington, D.C., in June 2006, they described the current situation:

"Traditionally, indigenous populations have suffered from disproportionately high rates of maternal and infant mortalities, malnutrition, and infectious diseases. However, these populations become more mobile, less isolated, increasingly urban, and located in border areas, issues such as use of drugs and alcohol, suicide, sexually transmitted diseases, and loss of influence of traditional health practices have become increasingly important. Although their disease burden and transitional-stage epidemiological profile is similar to other 


\section{Gould-Are We Happy Yet}

disadvantaged groups in the Region, their poor health status is compounded by discrimination and inequity within the health system. Indigenous populations comprise the majority in several countries and geographic areas, but $40 \%$ of the indigenous population lacks access to conventional health-related services and $80 \%$ rely on traditional healers as their principal health care provider."22

If several decades of international efforts in development have not painted a more positive picture of basic, physical well being, perhaps we should question the goals, priorities, and measurements of development to date. Even in the United States, where health and mortality statistics have been improving, Natives between 15 and 24 years of age commit suicide 3.3 times more than the rest of the country and 25-44 year old Native die from chronic liver diseases 7.1 times more than the rest of the US and from suicide 2.1 times more often. Native youth attend too many funerals. Two Ojibwe females in their early twenties told me they had been to more than twenty funerals in their lifetimes, several in the past year alone. Certainly, the grief and despair caused by high rates of illness and death in the community can have mental and behavioral health consequences, perhaps more so because these health disparities seem inevitably linked to being Indigenous.

Invisible to quantitative evaluations are the many social nuances particular to each community that are certain to be affected by economic changes for better or worse. For example, divisions within communities between "progressives" and "traditionalists" or even between extended families are exacerbated by controversial project proposals, especially when a community's economy is precarious. Examples of this include the recent trend toward reshuffling tribal enrollment once a tribe becomes wealthy or the violence stirred up between neighboring Ecuadorian tribes when tantalizing oil money is available.

In some cases, the indicators of success may not be compatible with Native ways of evaluation. One important concern is that only individuals' needs or benefits are measured, but the well being of the collective entity is not considered - also a problem with human rights, in some cases. Other criteria can be deeply mismatched, as 


\section{Ethnic Studies Review Volume 31}

in the Units States' General Allotment Act of 1887 (known as the Dawes Act), where the ideal was to create self-employed farmers through land legislation, or the Relocation policy of the 1950s where assimilation was seen as key to economic success; mechanization, as in a tortilla factory that did not replicate homemade taste; or the Green Revolution of the 1960s - 70s that created dependence on expensive chemicals and machinery as well as social divisiveness. All of these could have been measured based on increased productivity and judged successful programs. Top-down and onesize-fits-all projects, seemingly proven to be successful according to some criteria, have caused innumerable social consequences that perhaps could have been foreseen from an emic point of view. Project designers that are not endogenous are not place-based, can leave or be distant from the place of the project and can ignore (intentionally or unintentionally) a large amount of community and geographically specific knowledge needed for development to be successful in a lasting and significant way is can be overlooked in favor of established mainstream technology and methodology.

\section{Questioning Current Indicators}

If projects that successfully make economic change don't better well-being — for whatever reason — perhaps we are not evaluating success in a way that makes this happen. After all, criteria and evaluations inform the goals of subsequent projects.

While economic indicators tell us little about the non-material well-being of a community, social indicators tell us much more about health and happiness, as well as families and individuals' human development. However, neither tells us how they connect and whether any community projects affect a deeper and broader well-being. If evaluations make no connection between these, then how can anyone design new projects that will satisfy the needs, visions, and protocols of their community? Does the number of schools or student attendance tell us if students are smarter or better prepared for life with culturally relevant and appropriate intellectual development? Does increased participation in tribal or national government ensure consensus and cooperation? Does the number of hospitals or doctors tell us whether people are healthy 
- or does it say that there is such poor health that these services are in great demand? Whether the community is healthier or not, a large number of medical employees can lower unemployment rates and raise average income - even if the employees were hired from outside the area. In some cases, such as coal mines, more jobs have meant health, environmental, and/or family problems. Does the number of businesses in an Indigenous region indicate a level of sustainable self-sufficiency or imply dependence? Will social problems come attached to increased income? Does income level or employment rate tell us whether people feel that they are contributing members of their community? There is no question that schools, clinics, and jobs are important, but they are not the same thing as well-being. How does a Native community (or any community for that matter) recognize whether it is thriving on a meaningful, integral level or just improving the look of statistics?

For example, if a community with a casino hands out large per capita checks and has excellent health insurance and services but has an alarmingly high domestic violence rate, can this community be said to experience well-being? And is there a relationship between these two occurrences? In the Hñañhu community of San Pablito, the number of cement-block houses, cars, phones and toilets has risen thanks to income sent home by emigrant workers, but the community also has its first two cases of AIDS and an increase in abandoned children and elders (personal communication, Luisa Santos, November 2004). Similarly, the Navajo nation reported its first cases of AIDS in 1987, several years into the epidemic. What brought this about? Communities receiving emigrant or urban money may experience associated violence, assimilation, gender role shifts, dependence, language and knowledge loss, neglect of lands, single parent families and abandonment of children and elders - that one can hardly say with any certitude that the community as a whole is thriving more than it did before the young men went away to work.

\section{Challenging Universalized Criteria}

As academics and allies of grassroots practitioners, we can challenge universalized evaluation methods, which may be 


\section{Ethnic Studies Review Volume 31}

well-intentioned in their pursuit of equanimity, but are full of problems. The United Nations has been working on "Millennium Development Goals" which have identified universal goals addressing basic needs that people should not be without - but the measurement systems continue to work on a national level and don't always distinguish Indigenous people's status. Indigenous activists have voiced their concerns. In all fairness, the United Nations is a coalition of nation-states and must work within these structures, but this sort of evaluation can make it seem that Latin American countries are very close to meeting these MDGs, even though the Indigenous quality of life is often far from adequate. In the United States the disparity between statistics on education, infrastructure, employment for the nation and those for Lakota or Hoopa reservations is startling, as is the disparity between Mexico's national averages and Tarahumara communities, Brazil's and those of Indigenous Amazon communities, etc.

Fortunately, alternative indicators have emerged that clearly reflect the worldviews and values of their practitioners. For example, the Happy Planet Index, developed by the New Economics Foundation, incorporates three separate indicators: ecological footprint, life-satisfaction and life expectancy. Conceptually, it is straight forward and intuitive: HPI $=$ Life satisfaction $\times$ Life expectancy divided by Ecological Footprint. The HPI juxtaposes average years of happy life and planetary resources consumed to conclude that our resources can be better used toward the ultimate end of long, happy lives. "This conclusion is less surprising in the light of our argument that governments have been concentrating on the wrong indicators for too long. If you have the wrong map, you are unlikely to reach your destination." 23

This calculation rates economic powerhouses like the US, Canada and Russia lower while small island nations fare best, suggesting that money doesn't make you happier or make a better relationship between resource use and long, happy life. ${ }^{24}$

\section{Culturally-specific Evaluation}

Although they share some values and often collaborate, environmentalists and other allies are not identical to Indigenous 


\section{Gould-Are We Happy Yet}

people in their worldviews, values, social protocols, or goals. Nor are their futures inextricably linked to project outcomes. Fortunately, the stakeholders themselves, the Indigenous communities, are as capable of expressing their own values and evaluating their own projects as anyone. According to Tebtebba, an Indigenous organization based in the Philippines, the Dayak people of Indonesia have articulated their own criteria for community projects - Sustainability, Collectivity, Naturality, Spirituality, Process, Subsistence (domesticity) versus commerciality, Customary law versus global - and Tebtebba notes that "Failure to achieve these ideals is believed to result in barau ... a situation when nature fails to function normally, and thus results in chaos. Barau is a result of Adat transgression, a broken relationship with nature. 'Poverty' for the Dayak is linked directly with failure to exercise the Adat that governs the way in which the people should live." ${ }^{25}$

In Bhutan, after many centuries of voluntary isolation, government briefly pursued modernization and capitalist standards of progress and success. They found that, as Buddhists, this was not for them. At the1998 Millennium Meeting for Asia and the Pacific in Seoul, the Chairman of the Council of Ministers, Royal Government of Bhutan explained his country's philosophy of development and cautioned that although the standard of "Gross National Happiness" might seem idealistic, in fact his country was putting their King's vision into practice and policy.

"The academic community has not developed the tools we need to look at happiness, one of our primary human values. This has led to a paradoxical situation: the primary goal of development is happiness, but the subject of this very goal eludes our analysis because it has been regarded as subjective... Much is known about income disparities but nothing about the happiness gap either between social groups or between nations..."26

Certainly Indigenous people in the Americas live their worldviews as profoundly as the Dayak, the people of Bhutan or anyone else in the world, and alternatives specifically designed by and for Indigenous communities to reflect their values are not only possible, they are already on the table in international forums, 


\section{Ethnic Studies Review Volume 31}

contesting the universality of generalized evaluations that exclude their goals and evaluations. Based on recommendations from the third and fourth sessions, the Permanent Forum on Indigenous issues held the Technical Workshop on Indigenous Peoples and Indicators of Well-Being in Ottawa ${ }^{27}$, where discussants - including outspoken representatives from all over the Americas - noted that "dominant paradigm listening" and research methods often did not reflect Indigenous perceptions, and the misinterpretations allowed for a lack of research integrity. Certainly it will take considerable work to align culturally-specific Indigenous priorities for evaluation of well-being - such as traditional knowledge, self-government, and community/eco-system health - with broad Millennium Development Goals and nation-state priorities for data gathering. However, the discussants created a set of core and sub-themes and important indicators of Indigenous well-being. ${ }^{28}$

\begin{tabular}{|c|c|c|}
\hline Core Theme & Sub-Theme(s) & Examples of Indicators \\
\hline $\begin{array}{l}\text { Identity, } \\
\text { Land and } \\
\text { Ways of } \\
\text { Living }\end{array}$ & $\begin{array}{l}\text { Use and intergenerational } \\
\text { transmission of indigenous } \\
\text { languages } \\
\text { Support of, and access to, } \\
\text { bilingual, mother tongue, } \\
\text { and culturally appropriate } \\
\text { education }\end{array}$ & $\begin{array}{l}\text { Percent of indigenous } \\
\text { peoples' who recognize their } \\
\text { indigenous language as their } \\
\text { mother tongue } \\
\text { Percent of fluent indigenous } \\
\text { language speakers in } \\
\text { indigenous communities } \\
\text { Percent of children learning } \\
\text { indigenous languages } \\
\text { Number of programs to } \\
\text { transmit/learn indigenous } \\
\text { languages/culture } \\
\text { Use of indigenous languages } \\
\text { in state documents } \\
\text { Use of indigenous languages } \\
\text { in the media }\end{array}$ \\
\hline
\end{tabular}

Sample set of indicators from the Report Of The Meeting On Indigenous Peoples And Indicators Of Well-Being,Ottawa, 22-23 March 2006

It is interesting to note that these indicators do not seem to distinguish between individual well-being and the collective well-being of a community, people or nation. Some of these indicators can be transformed into project objectives that will 
lead to improvements in the areas listed here as sub-themes and strengthen the pursuit of their core goals. In the example above, increasing the number of fluent speakers would address the goal of maintaining transmission of cultural knowledge. On another core theme, reducing environmental protection violations and conservation damage within and near indigenous lands and territories can improve the overall health of the environment and by extension the community.

It is important to note that the criteria expressed in this report can be traced to roots in Indigenous values and worldviews. Worldview refers to collectively developed ways of understanding, guiding and valuing and can be loosely defined as an understanding of how the world does and should function, why things work as they do, and the role of humans in this world. Worldview affects our socialization, expectations, protocols, and assessment of what is a healthy and satisfactory life. Important elements of worldview are the foundation of many community projects, for example, in the instances of distributive justice or reciprocity defining integrated food programs, in Menominee logging when their relationship with their place tells them that the forest will sustain them indefinitely as long as they sustain the forest, or in the Pojoaque Pueblo's cultural and educational center which began from the prophecy that told them the little ones would lead them out of difficult times. ${ }^{29}$ Concepts of time, relationship to place, and interrelationship among all living things are all pieces of worldview that shape goals, methods, knowledge and protocols used to pursue improvements in well-being.

\section{Conclusion}

If projects measured by criteria that ignore Indigenous values have failed to resolve major social concerns, then revising evaluations to incorporate these values may very well produce results that are more and more adequately complex and satisfying to the Indigenous communities that practice them. Such revisions are already being applied with notable impact. These are based on the particular values of their designers, their sense of what is good and right, whether that worldview belongs to Buddhists, environmentalists, or Indigenous people of the Americas. Since 


\section{Ethnic Studies Review Volume 31}

evaluation criteria, goals and research design are all intertwined, it seems that simply allowing Indigenous people to be subjects, informants or participants limits the depth and usefulness of our work as researchers. As academics we can simply fulfill academic needs and expectations, comfortably analyzing from outside according to the criteria that suits our own ideas. Continuing along that path will mean we will eventually have to measure the effects of studies and projects that conflict with Indigenous peoples' worldviews. Or we can incorporate tailor-made, culturally-specific criteria as expressed by the groups of people that we work with to create assessments and analyses that contribute to work initiated and directed by communities themselves. My conclusion is that we can be more useful and give richer information if we design and direct research projects with Indigenous people and their goals, criteria, knowledge and methods, expanding the canons of our discipline a bit in pursuit of more relevant and rewarding results. In this way, perhaps the collaboration between academia and Indigenous communities can contribute to substantial improvements in wellbeing and contentment.

\section{Notes}

1 U.S. Census Bureau, American Indian- And Alaska Native-Owned Firms: 2002 Economic Census, Survey Of Business Owners, Company Statistics Series Issued June 2006

2 National Women's Business Council, Native American/Alaska Native Women And Entrepreneurship, $2006 \mathrm{Http}: / / \mathrm{Www}$.Nwbc.Gov/Researchpublications/ Documents/Native Amer Factsheet 2006.Pdf Accessed 10/20/2006

3 Taylor, Jonathan B. And Kalt, Joseph P. American Indians On Reservations: A Databook Of Socioeconomic Change Between The 1990 And 2000 Censuses, 2005, The Harvard Project On American Indian Economic Development Malcolm Wiener Center For Social Policy John F. Kennedy School Of Government, Harvard University, Cambridge, Ma

4 U.S. Census Bureau, American Indian- And Alaska Native-Owned Firms: 2002 Economic Census, Survey Of Business Owners, Company Statistics Series Issued June 2006

5 Kalt and Taylor, American Indians on Reservations: A Databook of Socioeconomic Change Between the 1990 and 2000 Censuses, 2005 


\section{Gould-Are We Happy Yet}

6 US Census Statistics for American Indian and Alaska Native-Owned Firms by Kind of Business: 2002

7 National Aboriginal Environmental Development Board, Ottawa, ON http:// www.naedb-cndea.ca/epic/internet/innaedb-cndea.nsf/en/wc00030e.html accessed 11/19/06

8 Harvard Project on American Indian Economic Development, Honoring Nations: Tribal Governance Success Stories, 2000

9 Small Business Administration: Native American Affairs, Http://Www.Sba. Gov/Naa/Tribes, Last Updated 2000, Accessed October 6, 2006

10 National Aboriginal Environmental Development Board, Ottawa, ON http:// www.naedb-cndea.ca/epic/internet/innaedb-cndea.nsf/en/wc00030e.html accessed 11/19/06

11 "Editor's Report: Indian Country Responds." Indian Country Today, October 01, 2001,

$<$ www.indiancountry.com/content.cfm?id=1822> Accessed November 22, 2006.

12 Norrell, Brenda, "Living In The Aftermath Of Two Killer Storms", Indian Country Today, <http://www.indiancountry.com/content.cfm? id=1096413755>, Accessed October 02, 2006.

13 Bregendahl, Corry And Flora. Cornelia, Native American Business Participation In E-Commerce: An Assessment Of Technical Assistance And Training Needs. 2002, North Central Regional Center For Rural Development, lowa State University, Ames, lowa

14 National Center For Health Statistics, Health, United States, 2005 With Chartbook On Trends In The Health Of Americans Hyattsville, Maryland: 2005

15 US Census, American Indian, Alaska Native Tables From The Statistical Abstract Of The United States: 2004-2005, Http://Www.Census.Gov/Statab/ Www/Sa04aian.Pdf, Accessed 10/20/2006

16 FIMI (International Indigenous Women's Forum) Report Release "Mairin Iwanka Raya, Indigenous Women Stand Against Violence" United Nations Permanent Forum On Indigenous Issues (Unpfii), October 17th 2006

17 National Aboriginal Environmental Development Board, Response to the Canada Aboriginal Peoples Roundtable Economic Opportunities Sectoral Follow-up Session Facilitators' Report Held in Ottawa on December 13 and 14, 2004 


\section{Ethnic Studies Review Volume 31}

18 Amnesty International, Canada. "Stolen Sisters - A human rights response to discrimination and violence against Indigenous women in Canada", 4 October $2004<$ http://www.amnesty.ca/resource_centre/reports/view.php?load=arcvie $w \&$ article $=1895 \& c=$ Resource + Centre+Reports $>$, Acccessed May, 2007.

19 Amnesty International, Canada. "Stolen Sisters - A human rights response to discrimination and violence against Indigenous women in Canada", 4 October 2004 <http://www.amnesty.ca/resource_centre/ reports/view.php? load $=$ arcview \&article $=1895 \& c=$ Resource + Centre $+R$ eports>, Acccessed May, 2007.

20 Comisión Nacional Para El Desarrollo De Los Pueblos Indígenas, "Indicadores socioeconómicos de los pueblos indígenas "Mexico City, http://cdi.gob.mx/ index.php?id_seccion=91, accessed 12/10/06

21 Hall, Gillette And Patrinos, Harry Anthony Indigenous Peoples, Poverty And Human

Development In Latin America: 1994-2004

22 "Health Of The Indigenous Population In The Americas", Presented To The $138^{\text {th }}$ Session Of The Executive Committee In Washington, D.C., In June 2006

23 The New Economics Foundation Http://Www.Happyplanetindex.Org/ Reveals.Htm 2006 Visited 9/2/06

24 Ibid

25 Cariño, Joy, Indigenous Peoples, Human Rights And Poverty, Indigenous Perspectives, Volume 7, Number 1, April 2005, Tebtebba Foundation, Phillipinnes

26 Thinley, Lyonpo Jigmi Y. Values and Development: "Gross National Happiness" Text of the Keynote Speech Delivered at the Millennium Meeting for Asia and the Pacific, 30 October 1 November 1998 Seoul, Republic of Korea His Excellency Chairman of the Council of Ministers Royal Government of Bhutan

27 Report Of The Meeting On Indigenous Peoples And Indicators Of WellBeing, Permanent Forum on Indigenous Issues, E/C.19/2006/CRP.3 Ottawa, 2223 March 2006

28 Report Of The Meeting On Indigenous Peoples And Indicators Of WellBeing, Permanent Forum on Indigenous Issues, E/C.19/2006/CRP.3 Ottawa, 2223 March 2006

29 Guyette, Susan Planning for Balanced Development: A Guide for Native American and Rural Communities Santa Fe, NM: Clear Light Publishers, 1996 